This paper reports the system of devised technologies for harvesting hemp with belt hemp threshers. It is proposed to form a roll of mowed hemp stems on a belt and tramp it to the field edge for further processing of stems. That makes it possible to significantly improve the efficiency of mechanized processes when harvesting and processing the entire biological harvest of hemp. Thus, the level of handling hemp production systems has been increased. At the same time, the management of the process of roll formation of hemp stems has been improved.

The technology of hemp harvesting has been improved with the possibility of obtaining raw materials for long fiber and therapeutic preparations. Two-phase harvesting (for seeds and fiber) has been proposed to be implemented by using belt hemp threshers included in the stationary (semi-stationary) complexes.

The possibility of preparing the combed hemp retted stalks by spreading them on materials of various types has been systematically substantiated.

The influence of the thickness of a layer of hemp stalks spread out for the preparation of retted stalks on the timing of their preparation and fiber quality indicators has been investigated.

It was established that in terms of the quality indicators of the produced fiber, the retted stalks from all experiments are properly aged while the efficiency of their processing for medium-and large-stalk fraction is high.

The fibers produced in all experiments were characterized by purity, as well as high indicators of breaking load and handful length.

As regards the linear density, the fibers' values in all experimental variants exceeded the normative ones by 1.65-2.64 times, which rendered them non-standard.

An increase in the values of quality indicators has been established with the corresponding change, from 1 to 3 kilograms per meter, in the thickness of the layer of combed hemp stalks. The breaking load, under such conditions, increased by $16.6 \%$; the linear density, by $20 \%$; the content of shives, by $60 \%$; the paw content, by $12.5 \%$, the content of bast strands, by $10.8 \%$

Keywords: industrial hemp, belt harvesting technology, shale retted stalks, retted stalk quality
UDC 633.522

DOI: $10.15587 / 1729-4061.2022 .251126$

\section{DEVISING TECHNOLOGIES FOR HARVESTING HEMP WITH BELT THRESHERS}

Viktor Sheichenko Correspondingauthor

Doctor of Technical Sciences, Professor

Department of Technology and Means of Mechanization of Agricultural Production**

E-mail: vsheychenko@ukr.net

Vitaliy Shevchuk

$\mathrm{PhD}$, Senior Researcher

Department of Agricultural Engineering Uman National University of Horticulture Institutska str., 1, Uman, Ukraine, 20305

I gor Dud n i k o v PhD, Associate Professor*

Serhi Koropchenko

$\mathrm{PhD}$, Senior Researcher

Department of Engineering-Technical Researches Institute of Bast Crops of the National Academy of Agrarian Sciences of Ukraine

Tereschenkiv str., 45, Hlukhiv, Ukraine, 41400

Viktor Dnes

$\mathrm{PhD}$

Department of Simulation of Technological Systems and the Market of Technical Service in Agro-Industrial Production National Scientific Center «Institute of Agricultural Engineering and Electrification» Vokzalna str., 11, Hlevakha, Ukraine, 08631

Yuliia Skoriak $\mathrm{PhD}$, Assistant*

Volodymyr Skibchyk

$\mathrm{PhD}$

Department of Labor Protection and Biotechnical Systems in Animal Husbandry National University of Life and Environmental Sciences of Ukraine Heroiv Oborony str., 15, Kyiv, Ukraine, 03041 *Department of Industrial Machinery** **Poltava State Agrarian University Skovorody str., 1/3, Poltava, Ukraine, 36003
Received date 21.11.2021 Accepted date 13.01.2022 Published date 24.02.2022
How to Cite: Sheichenko, V., Shevchuk, V., Dudnikov, I., Koropchenko, S., Dnes, V., Skoriak, Y., Skibchyk, V. (2022). Development of harvesting technologies with belt accessories. Eastern-European Journal of Enterprise Technologies, 1 (1 (115)), 67-75. doi: https://doi.org/10.15587/1729-4061.2022.251126

\section{Introduction}

Hemp cultivation is a dynamically developing industry. The commercial attractiveness of industrial hemp, the public demand for goods and products from it, put forward increased requirements for techniques and methods that could enable deep enough processing of all components of the crop.

The modern development of hemp cultivation is characterized by certain features. Owing to the achievements of breeding science, new generation varieties have been created for different applications, as well as the varietal technologies 
of their cultivation. These new varieties of crops can yield seed harvest at the level of 15-20 hundred kilograms per hectare (hkg/ha), against $8-12 \mathrm{hkg} / \mathrm{ha}$, which is currently observed [1].

Industrial hemp is a promising technical crop with a significant reserve of potential opportunities. Given the consumer properties of hemp, the scope of its application covers a wide range, including food, construction, automotive, bioenergy, textile, cellulose and paper, pharmaceutical, medical industries, etc. The world market has currently more than 25 thousand goods from hemp raw materials [2].

Note the increased investment attractiveness of hemp cultivation. The industry is developing rapidly and dynamically. Analysis of the global market demand for hempbased products shows the prospects and economic attractiveness of medical use, in particular. During 2018-2020, the European market for the use of hemp plant for medical, pharmaceutical, and therapeutic purposes significantly increased. Not surprisingly, over 1 billion euros were invested in the medical hemp market over that period.

Hemp stalk is the most valuable part of the plant. It contains bark (bast) in which fiber is formed. From the outside, the bark is covered with an epidermis, and on the inside, it is confined to cambia and wood, in the middle of which there is a core. Primary and secondary bast fibers are formed in the bark. Primary fiber is more valuable because it has a higher quality.

The development of technological processes of hemp production increasingly requires new technical and technological solutions that would make it possible to solve the problem of the effectiveness of further mechanization of the production of this industrial crop in general.

The above-mentioned issues are very important; resolving them is of great importance for improving technologies and equipment at the stages of harvesting, transportation, and primary processing of all components of the biological hemp harvest. Given the results demonstrated, the steps to transfer the production of hemp-based goods to highly profitable technologies, which could ensure its competitiveness, look promising.

\section{Literature review and problem statement}

Industrial hemp is characterized by two periods of ripeness. That is why two terms are used for its harvesting - for fiber (greens) and seeds, and for fiber (two-sided use). The scenario of implementation of the harvesting technology determines the priorities of a particular raw material (straw or retted stalks) from which one subsequently receives long or short fibers, or fiber in the form of a random array. Timely hemp harvesting makes it possible to produce high quality goods and provides for the profitability of hemp cultivation. The highest yield of seeds, straw, and fibers with two-sided use is ensured by harvesting single-domed hemp plants during the ripening period of $75 \%$ of seeds in most plants. Earlier harvesting is impractical as it leads to a shortage of $18-54 \%$ of the seed crop while the delay in harvesting increases its losses to $24-61 \%$ [3]. The disadvantages of classical harvesting technologies include their narrow focus. Under such conditions, a certain part of the crop is lost.

Green crops are to be harvested while $10-50 \%$ of seeds are ripened when the formation of crops providing for fiber quality is completed.

Classic harvesting technologies mainly focused on obtaining the maximum amount of long fiber. Under such conditions, it was impossible to do without the use of special, expensive hemp harvesting equipment.

Due to the low productivity of specialized machinery, the small volume of its annual loading, the need to attract a significant reserve of human labor, classic technologies have not been widespread [4].

Harvesting dual-use hemp under current industrial conditions involves the use of general-purpose agricultural machinery with the separation of the main produce (seeds and fibrous raw materials) in several stages. At the first stage, the seed component of the crop is harvested using combine harvesters. Preference is given to combine harvesters with a higher lifting height of the harvester and a keyboard type of straw shaker. When a combine harvester operates, the indicators of damage to the seeds are controlled. Particular attention is also paid to preventing windings of the straw part of the crop on rotating working bodies.

Hemp stalk harvesting is carried out using agricultural equipment of general purpose: mowers, rakes, rolls, press pickers, etc. Technological regulations for the use of technology, the sequence of operations depend on the goals set by research [5]. However, the specified harvesting technologies cannot utilize the full potential of the plant. Therefore, their effectiveness is not high.

Primary hemp processing consists of two production cycles: the preparation of retted stalks and the processing of retted stalks into fiber.

Existing methods of retted stalks preparation, in terms of the mechanisms that destruct bonds between fibers and tissues in the stalk, are divided into biological, chemical, and physicochemical [6].

The most common and widespread technique of primary hemp processing is the separation of fiber from straw, converted in advance into retted stalks by biological wetting.

The most important task of primary processing is the most complete separation of fibers from stalks provided the maximum volume of long fiber, which is the most valuable type of produce for industrial and household use [7].

Microorganisms, bacteria, and fungi are the main «creators» of the biological method of destroying bonds between the fiber and tissue in the hemp stalk. In the process of their vital activities, fungus spores produce substances (enzymes) that cause the destruction of pectin substances and disrupt the connection between tissues [8].

The most common ways to make hemp retted stalks are cold water and warm water wetting. The preparation of hemp retted stalks by spreading out the straw on beds, similar to flax retted stalks, is characterized by a deterioration in the quality of fiber from the shale retted stalks. Thus, the yield of long fiber according to the shale method, compared to the wetting method, is $66 \%$, the average number of long fibers is 5.2 vs. 6.6 ; short -1.7 vs. 2.0 , the number of retted stalks is 0.7 vs. 0.9 at wetting [9]. However, this technique is not widespread due to significant financial costs.

When a chemical technique is used for obtaining retted stalks, the destruction of bonds between the fiber and wood in hemp stalks is due to the application of chemicals. The effect of chemicals makes it impossible to decompose pectin and other substances into simpler ones, and leads, ultimately, to their destruction [10]. However, the significant financial and economic costs of implementing this technique of retted stalk preparation are deterrent to its widespread application.

The physicochemical method is implemented through the destruction of bonds between the fiber and wood in the 
process of thermochemical hydrolysis when using steam and high temperature.

It should be noted that each of the known techniques for preparing hemp retted stalks is characterized by a number of features, has advantages and disadvantages. The most common, simple, and cheap method is a method for moisturizing stems by dew. The specified method does not require the involvement of additional resources, eliminates the need for the construction of treatment facilities, while the number of workers involved can be reduced to a minimum [11].

The process of preparing hemp retted stalks has been studied in detail and covered in the scientific literature. However, the researchers ignored the questions that are due to the influence on this process by the development of modern technological processes. First of all, they include those that are aimed at energy saving, increasing the efficiency of all chains (stages) of production and processing of the entire volume of biological crop [12].

Belt technologies for harvesting and transporting hemp stems look promising. These technologies provide for the following:

- favorable conditions for managing the process of roll formation of hemp stalks;

- increasing the level of controllability of production systems, due to the compact arrangement of the crop at specially prepared fields with the possibility of phased processing of all parts of the crop.

Changes in weather and climatic conditions observed in the current development of agricultural production should also not be overlooked. Undoubtedly, these changes have a significant impact on the technological diversity of the modern stage of industry development. The time has finally come for comprehensive research aimed at taking into consideration the noted factor and assessing its impact on the stages of retted stalks preparation in those existing natural and climatic zones where hemp is cultivated.

\section{The aim and objectives of the study}

The purpose of this research is to devise technologies for harvesting industrial hemp stalks using belt hemp threshers, which would make it possible to improve the efficiency of crop cultivation.

To accomplish the aim, the following tasks have been set:

- to devise technological schemes for harvesting industrial hemp by using belt hemp threshers;

- to establish the effect of the coating (film, tarpaulin, concrete surface, asphalt) used for spreading out hemp stems for preparing retted stalks, on fiber quality indicators;

- to establish the effect of the thickness of a layer of hemp stems spread out for the preparation of retted stalks, on the duration of their preparation and fiber quality indicators.

\section{The study materials and methods}

The object of our research is technological processes, plant material, the working bodies of machines and assemblies for harvesting, transporting, and primary processing all components of the biological hemp crop.

Our scientific hypothesis assumes that an increase in the technical and technological level of modern hemp cultivation largely depends on the scientific substantiation of ways to manage the quality indicators of all parts of the biological crop of industrial hemp, which, in turn, could be ensured through the development of technologies for harvesting crop stems using belt hemp threshers.

Our experiments were carried out at a site for drying (preparation of retted stalks), which met the following requirements:

- it was located in an open smooth terrain;

- it had no trees and bushes.

The program of the experimental research involved the following numbering of experiments:

1. Spreading out on grass, control, combed hemp stalks, 1 kilogram per meter.

3. Spreading out on a film without holes, combed hemp stalks, 1 kilogram per meter.

8. Spreading out on tarpaulin, combed hemp stalks, 1 kilogram per meter.

9. Spreading out on a white film without holes, combed hemp stalks, 2 kilograms per meter.

10. Spreading out on a white film without holes, combed hemp stalks, 3 kilograms per meter.

12. Spreading out on concrete, combed hemp stalks, 1 kilogram per meter.

13. Spreading out on asphalt, combed hemp stalks, 1 kilogram per meter.

14. Combed stalks in sheaves weighing $1 \mathrm{~kg}$ in cyclones.

Our research methodology implies that the color of stalks is regularly, for no longer than 7 days, determined by the organoleptic method, the color of the stalks is checked by a device; the indicator of fiber separation is also determined. If necessary, stalks are rotated.

Changes in the color of hemp stalks were determined organoleptically; for comparison, we used the device OVL-1, which was specifically designed to measure the color of the flax stems.

In the case of disputes, when using an organoleptic assessment of the degree of aging of hemp retted stalks, we additionally determined the intensity of the reflected light flux by the surface analyzed. To this end, upon establishing the clogging, two samples of approximately the same mass were taken, sufficient to fully cover the bed of the device for determining the flax aging OVL-1 without illuminating its surface.

After placing the stems on the bed of the device, they are covered on top with a lightproof box and, in accordance with the manual, we acquire the readings from the scale. The top, near-stem, and middle zones of each sample were analyzed. A sample of retted stalks is then turned $180^{\circ}$ so that its upper and lower surfaces are swapped relative to the bed of the device. Similarly, indications of the intensity of the reflected luminous flux on the opposite side are acquired. In the same way, the second sample is analyzed. We determine the average value of the intensity indicator of the reflected luminous flux from 12 measurements to the first decimal sign, and then rounding the result to an integer. The degree of aging of hemp retted stalks was determined from Table 1.

We determined the degree of hemp retted stalks aging according to the indicators of separation and the intensity of reflected light flux by the analyzed surface while using technologies that make it possible to preserve the total length of stalks. Under such conditions, the stalks are analyzed without violating such indicators of their structure as breaking, splitting, tearing, etc.

The fiber separation rate, established both by the organoleptic method and by the device, was determined in different 
parts of the stem. Reproducing the experiments three times, we determined the average value that was entered in the Table 1.

Table 1

Gradation of the estimation of the degree of aging of hemp retted stalks

\begin{tabular}{|c|c|c|}
\hline Study object & $\begin{array}{c}\text { Reflected lumi- } \\
\text { nous flux, lux }\end{array}$ & Aging degree \\
\hline \multirow{3}{*}{ Hemp retted stalks } & less than 23 & aged retted stalks \\
\cline { 2 - 3 } & $23-27$ & under-aged retted stalks \\
\cline { 2 - 3 } & exceeding 27 & straw \\
\hline
\end{tabular}

Quality indicators were evaluated in accordance with the provisions of acting regulatory documents [13-15].

\section{Results of studying the techniques for gathering the biological harvest of hemp by belt hemp threshers}

\subsection{Devising technological schemes for harvesting} industrial hemp by belt hemp threshers

Based on the results of many years of research and observations, a belt technique for harvesting and transporting hemp stalks to the edge of a field has been proposed. Under such conditions, the stalks cut with a thresher are laid in the form of a continuous roll on a belt that is pre-lined under it (under the roll). The belt is spread out simultaneously with the process of forming a roll (Fig. 1, $a$ ) or in advance lengthwise the run (Fig. 1, $b$ ). During loading, the belt can be immobile with respect to the soil or slide on the stubble along with the beveled stalks of hemp entering it. In the case when the belt slides along the stubble at a speed of less than the speed of movement of the thresher, there is an increase in the mass of the roll's running meter due to a decrease in its length. This phenomenon is extremely important in terms of the roll formation process. The implementation of this phenomenon is of great practical importance, especially in the case of the formation of rolls with a predetermined mass of stalks per one running meter. Thus, due to adjusting the speed of movement of the belt relative to the moving thresher, it is possible to smoothly change the mass of one roll's running meter, which is formed not only on the belt but also on the stubble. Note that this can be done at the unchanged width of the working grip of the harvesting unit.

The roll formed on the belt can be transported (pulled) along the belt along the run (not necessarily straightforward) to the place of threshing (combing) or unloading of mowed hemp stalks. This means that the belt hemp thresher can be used as a special type of wheel-free vehicle to move the roll of mowed hemp stalks, and similar materials, within a field. We note the possibility of accumulation and transportation of a roll of mowed hemp stalks on a belt hemp thresher in order to adopt an assumption (hypothesis) regarding the feasibility of applying this idea to improve techniques of hemp harvesting. When forming mowed hemp stalks with fully ripe seeds on the belt, it is advisable to give priority to this very concept. Upon the separation of seeds, the stem mass has significant potential for further processing. In the future, you can imagine that the belt from its loading is rolled, gradually pulling along with the roll, and overloading the stalks of hemp from the belt to a stationary complex of machines.
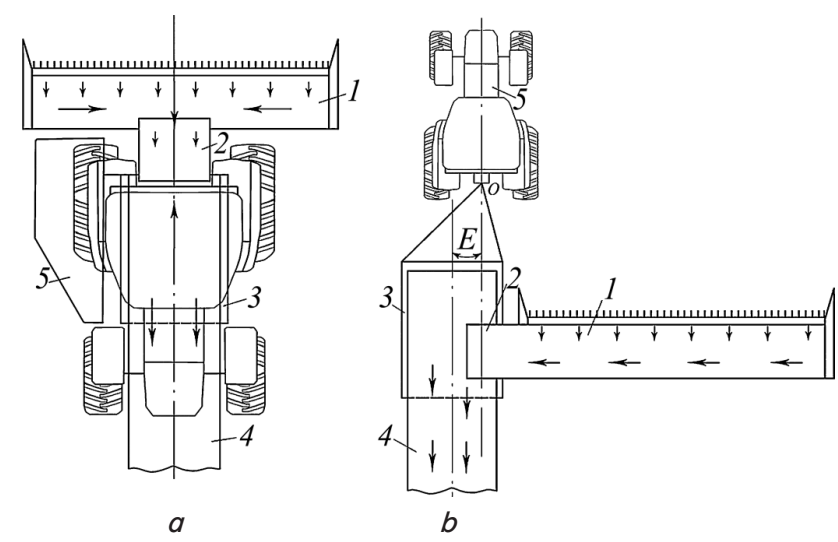

Fig. 1. Schematic showing the roll formation on a belt: $a-$ spread out in the process of forming the roll;

$b$ - pre-spread; 1 - harvesting system; 2 - transporter of mowed hemp stalks; 3 - belt roll; $4-$ a roll of hemp stalk mass; 5 - mobile threshing system (combine harvester)

The proposed technique for accumulating mowed hemp stalks on the belt can be the basis of a fundamentally new technique to form rolls on the stubble with a predefined mass of stalks per one running meter. Under such conditions, the mowed stalks of hemp are laid in the form of a roll on a belt, which is released at a speed lower than the speed of movement of the harvesting unit (Fig. 4). At the end of the run (not reaching the edge of $200 \ldots 250 \mathrm{~m}$ ), the belt begins to pull up to the harvester, without stopping the movement of the harvesting unit. Earlier accumulated stalks coming from the belt are unloaded on the stubble, combining them with a stream of freshly mowed stalks. By the time of reaching (moving to) the end of the run, the thresher and belt are completely freed from the mowed stalks of hemp. Under such conditions, the empty belt is rolled up. Thus, after unloading the mowed stalks from the belt to the stubble, it becomes possible to execute another working run of harvesting units.

Under this technique of forming rolls, the entire volume of mowed hemp stalks is concentrated at the ends of the run on a small part of the field.

Note the following technologies of hemp harvesting using belt hemp threshers, which potentially create preconditions for processing the entire volume of the biological crop:

1. Harvesting in the phase of «green» ripeness.

Note the focus of this technique on obtaining high-quality long fiber. However, along with the possibility of implementing this highly effective concept, there are real prospects to use mechanized technological techniques for harvesting part of the crop for the preparation of medicinal products. It should be noted that until recently, the separation and harvesting of hemp leaves were carried out mainly by hand.

The stages of technology implementation include combing the stalks on the edge of a field and obtaining valuable raw materials in the form of leaves and seed part (Fig. 2). Without a doubt, this type of product has an extremely high economic potential.

Rolls, or bunches, are formed from combed stalks. This is the raw material for the preparation of retted stalks with predicted parameters. It is important to note that at this stage it is possible to apply elements of intensification (management) of processes of biological transformation of stalks into retted stalks. These include flattening, softening of stalks, their pruning for predetermined dimensions, artificial moisturizing, laying on a belt with certain features, rotation, etc. 
Thus, owing to the proposed technique, it becomes possible to harvest and further use the green part (leaves and seed), shives, cropped parts of the stalks, retted stalks (long fiber).

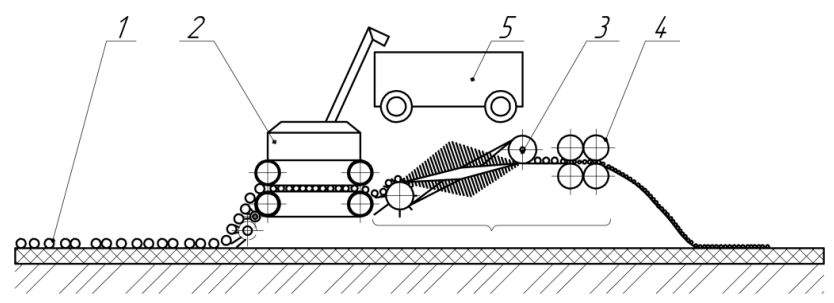

a

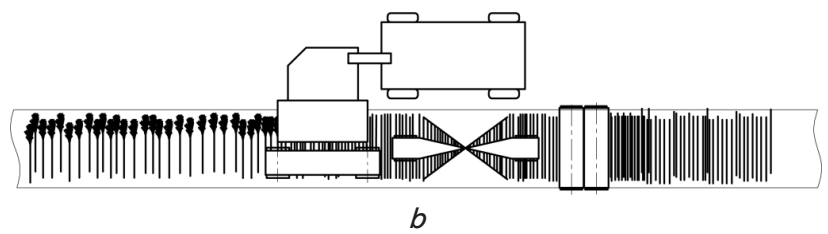

Fig. 2. Schematic showing a semi-stationary unit for combing the seed part and preparing stalks for the preparation of retted stalks using belt hemp threshers: $a$ - side view, $b$ - top view; 1 - hemp stalks on a belt hemp thresher; 2 - equipment for combing the seed part of hemp; 3 - flipping of combed stalks; 4 - equipment for the destruction of stalks by flattening; 5 - storage tank for combed seeds and heaps

\section{Two-phase harvesting - for seeds and fiber.}

The technology of processing the entire biological crop of hemp, which includes mowing, laying the stalks parallel to each other on the belt, pulling (transporting) the belt, combing the stalks with the subsequent production of seeds. The technology differs in that the belt with stalks is pulled to a stationary (semi-stationary) unit. The unit includes a combing device, knives for cutting (formation of stalks according to predetermined dimensions) combed seed part and butts, a site for turning the direction of movement of stalks by $90^{\circ}$, a single-pair flattening mechanism (Fig. 2). This mechanism consists of smooth (lower) and ribbed (upper) rollers located on top of each other and rotating in opposite directions.

The belt hosting the stalks arranged in parallel is pulled to the receiving chamber of the combing device, or the device moves along the field and executes stalk combing, dividing the combed mass into fractions and obtaining seeds. After combing the seed part, the stalk enters the zone of destruction of its integrity, it rotates, and it returns, with the preservation of parallelism, on the belt, which is spread out on the surface of the field.

It should be noted that the technologies of harvesting the entire biological crop end with (conditionally) comparative states and positions in the space of harvesting products. For example, seeds should be delivered to threshing-floor and brought to marketable condition; the stalks, the green part, the trimmed parts, shives, etc. are sent for further processing.

\section{2. Results of studying the effect of different types of} coating on the duration of retted stalks preparation

Our study was carried out in order to determine the effect exerted on the quality indicators of fiber by different types of coating upon which hemp stalks are spread out for preparing retted stalks.

The combed stalks of hemp in the amount of 1 kilogram per meter were spread out on different types of coatings. The following types of coatings were chosen: grass (control, experiment 1 (Fig. 3,a)); a polyethylene film without holes (experiment 3, (Fig. 2,b)); tarpaulin (experiment 8, (Fig. 3, c)); concrete (experiment 12, (Fig. 3,d)); asphalt (experiment 13, (Fig. 3,e)).

The experiments were carried out under the conditions of a forest-steppe natural-climatic zone at the research sites of the Institute of Bast Cultures, the National Academy of Agrarian Sciences of Ukraine. The stalks in all experiments were laid for preparing retted stalks at the same time.

The color of the stalks changed from yellow-brown with green shades, yellow-brown without gray shades of yellow-brown with the beginning of the manifestation of gray traces, yellow-brown with a significant number of gray traces, brown with a significant number of gray traces.

In all experiments, the indicator of a stalk color at the initial stage was yellow-brown with green shades. The nature of changing the color of the stalks in all groups was the same. After 29 days of aging, the indicator «stalk color» was re-determined. The following value of the specified indicator was established in the experiments: 1 - brown with a significant number of gray traces; 3,8 - yellow-brown with gray tracks; 12 - yellow-brown with a slight manifestation of gray traces; 13, 14 - yellow-brown with gray traces.

At that time, all stalks did not demonstrate the separation of fibers from the wood part (the indicator was determined by the organoleptic method). The stalks in all experiments were rotated on day 36 of aging.

On day 43 of aging, the following values of the stalk color indicators for the selection and separation were determined, respectively:

- experiment $1-18.5$ lux, there is no separation (the separation of two stalks in the middle part);

- experiment $3-20.5$ lux, there is no separation (the separation of five stalks in the middle part);

- experiment $8-21.5$ lux, there is no separation (the separation of three stalks in the middle part);

- experiment 12 - 19.5 lux, there is no separation (the separation on one stalk in the middle part);

- experiment 13 - 21.5 lux, there is no separation (the separation of three stalks in the middle part);

- experiment $14-36.0$ lux, there is no separation (the separation in one stalk in the middle part).

The separation of fibers in the experiments $(1,3,8,12,13)$ with spreading out the stalks was established on day 50 after the start of the experiment. The average of «stem color» indicator in experiments 1, 3, 8, 12 was 18.0 lux, and 18.5 lux in experiment 13 , respectively.

It should be noted that on day 50 of aging, in experiment 14, the color of the stalks, determined by the organoleptic method, was brown with a significant number of gray traces, the value of the indicator «the color of the stalks» is 28.0 lux, the separation was on only one stem. The state of the «gray-brown» stalks in this experiment was reached on day 78 , the value of the indicator «the color of the stalks» was 23.5 lux, the separation on several stalks in the middle part (the retted stalks are not aged).

The completion of the stage of retted stalks preparation in experiment 14 took place on day 157 according to the achievement of the indicator of the color of the stalks «gray». Under these conditions, the average color of the stalks was 25.3 lux, the separation on most stalks (the trust is aging down). The total duration of retted stalks preparation in that experiment was 3.14 times longer than that in experiments with the spreading of stalks. 


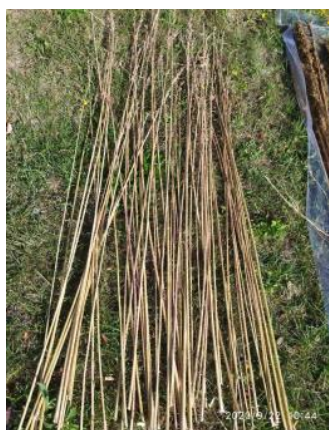

a

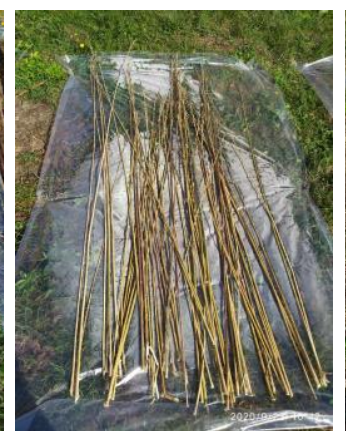

$b$

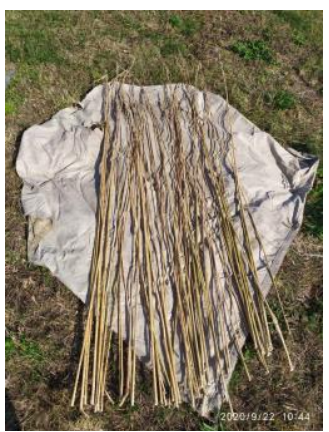

c

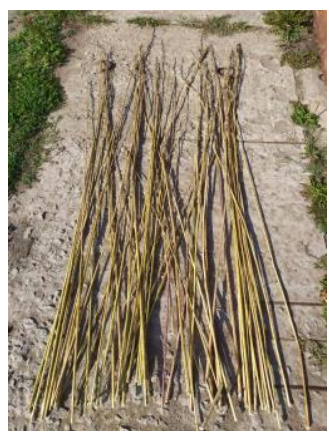

d

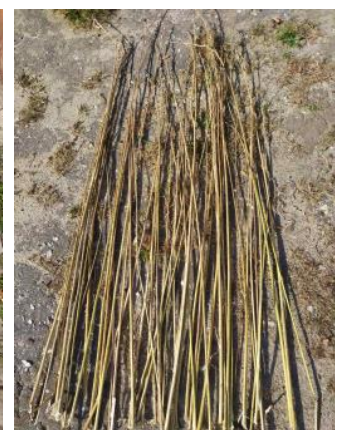

e

Fig. 3. Hemp stalks, combed and spread out in the amount of 1 kilogram per meter for preparing retted stalks: $a$ - grass; $b$ - polyethylene film without holes; $c$ - tarpaulin; $d$-concrete; $e$ - asphalt

Analyzing the results of experiments $(1,3,8,12,13)$ and 14 , we note a certain discrepancy in the indicators of retted stalks preparation. In experiments $1,3,8,12,13$, the fiber was separated from wood on day 50 of aging. The stalks in these experiments had a gray color and a dark gray color; the organoleptic score from the device was 18.0-18.5 lux. However, in experiment 14, the separation was recorded on day 157 with grey-colored stalks and a slightly higher reading from the device, 25.3 lux.

We have analyzed the values of long fiber quality indicators (Table 4). It is noted that according to the indicator of the breaking load, the long fiber of hemp in experiment 8 (spreading out on tarpaulin, combed stalks, 1 kilogram per meter) belongs to the first grade ( $32.4 \mathrm{daN})$. Of the third grade was the fiber from experiments 3, 12, 13; 14 (spreading out on a film without holes; on concrete; on asphalt; combed stalks in sheaves, weighing $1 \mathrm{~kg}$ in cyclones) with a breaking load, respectively: 25.3 daN; 25.8 daN; 25.1 daN; 25.6 daN.

According to the linear density indicator, the smallest values of the indicator are demonstrated by fibers from the retted stalks prepared on tarpaulin. However, the linear density indicator in all variants of experiments exceeds the normative value (50 tex).

The value of linear density in all variants of experiments exceeded the normative value by $1.65-2.64$ times, which rendered the fiber non-standard according to this indicator.

Based on the indicator of the content of bast strands, the fiber from all experiments corresponds to the second grade, in terms of the content of shives and paw - the first grade.

According to the quality indicators of the produced fiber, there is a certain similarity of different options since in all variants the retted stalks were properly aged, the efficiency of their processing for the medium- and large-stalk fraction, selected for experiments, was high. The fiber produced was practically clean in all experiments, with high breaking load indicators, as well as handful length, but the linear density in all variants exceeded 50 tex. Therefore, in terms of this indicator, the fiber is non-standard. A high linear density indicator can only be explained by the raw materials used in the experiment (large stalks and seeds taken after harvesting), in which the fiber has already become coarser.

According to the requirements of regulatory documents [13-15], the assessment was carried out according to the worst indicator, which is the indicator of linear density. Thus, the fiber from all experiments should be attributed to non-standard (Table 2).

The quality indicators of the fiber obtained from the retted stalks aged on tarpaulin, compared to the fiber from the retted stalks on a film, asphalt, and concrete, are characterized by higher values of the breaking load indicator.

\section{3. Results of determining the effect of the thickness} of a layer of hemp stalks on the duration of their preparation and fiber quality indicators

The density of hemp stalks on the belt is an important indicator that affects the duration of retted stalks preparation and the quality of the fiber. In an experiment to determine the effect of density, the combed stalks were spread out on a white film without holes. The spreading was carried out according to the following scheme: 1 kilogram per meter (experiment 3, (Fig. 3,a)); 2 kilograms per meter (experiment 9, (Fig. 4, $b$ )); 3 kilograms per meter (experiment 10, (Fig. $4, c)$ ).

The experiments were executed simultaneously, under the same natural and climatic conditions, in the same terrain.

Our research methodology implies that the color of the stalks is regularly, no longer than in 7 days, determined by the organoleptic method; the color of the stalks was determined by a device, as well as the indicator of separation of fibers. If necessary, the stalks were rotated.

Table 2

Quality indicators of hemp long fiber from the shale retted stalks of various preparation options

\begin{tabular}{|c|c|c|c|c|c|c|c|}
\hline $\begin{array}{l}\text { Experiment } \\
\text { No. }\end{array}$ & $\begin{array}{l}\text { L hand- } \\
\text { ful, cm }\end{array}$ & $\begin{array}{c}\text { Breaking load, } \\
\text { daN }\end{array}$ & $\begin{array}{c}\text { Linear } \\
\text { density, tex }\end{array}$ & $\begin{array}{l}\text { Shives } \\
\text { content, \% }\end{array}$ & $\begin{array}{c}\text { Paw } \\
\text { content, \% }\end{array}$ & $\begin{array}{c}\text { The content of bast } \\
\text { strands, \% }\end{array}$ & Grade \\
\hline 1 & 198 & 26.0 & 103.0 & 0.6 & 1.6 & 3.6 & non-standard \\
\hline 3 & 119 & 25.3 & 110.0 & 0.5 & 1.6 & 3.7 & non-standard \\
\hline 8 & 195 & 32.4 & 82.6 & 0.6 & 1.6 & 3.9 & non-standard \\
\hline 12 & 196 & 25.8 & 106.7 & 0.5 & 1.7 & 3.7 & non-standard \\
\hline 13 & 195 & 25.1 & 124.0 & 0.6 & 1.6 & 3.8 & non-standard \\
\hline 14 & - & 25.6 & 110 & 1.5 & 0.7 & 3.6 & non-standard \\
\hline
\end{tabular}




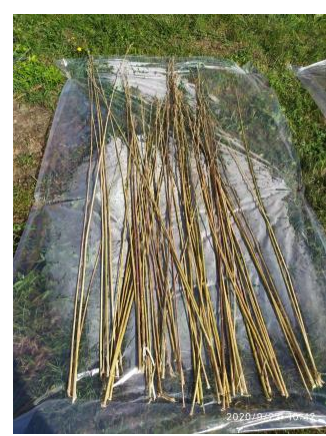

a

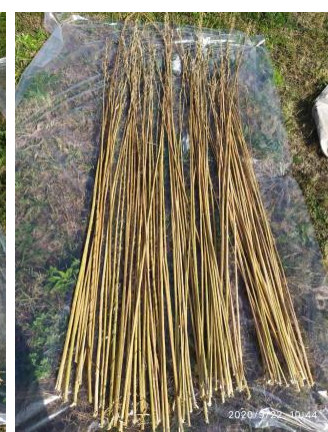

$b$

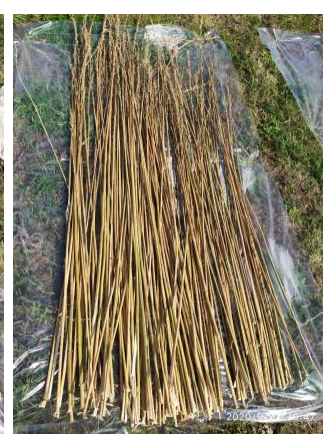

C
Fig. 4. The combed stalks of hemp, spread out on a white film without holes for the preparation of retted stalks in the amount: $a-1$ kilogram per meter; $b-2$ kilograms per meter; $c-3$ kilograms per meter

The stage of preparing the retted stalks in all experiments took place under the same conditions; it was characterized by a similar duration and ended in one day. The total duration of retted stalks preparation was 50 days when spreading out them on a white polyethylene film.

The indicator «the color of the stalks by organoleptic method» at the stages of preparation of the retted stalks in all experiments was the same.

The stalks were rotated once every 36 days of aging. The results of determining the indicator of the color of the stem by a device are given in Table 3 .

Table 3

The results of studying the indicator «the color of the stalks by a device, lux» at the stages of retted stalks preparation

\begin{tabular}{|c|c|c|c|}
\hline \multirow{2}{*}{$\begin{array}{c}\text { Day of } \\
\text { aging }\end{array}$} & $\begin{array}{c}\text { Experiment } 3 \\
\text { Stalk color by } \\
\text { a device, lux }\end{array}$ & $\begin{array}{c}\text { Experiment } 9 \\
\text { Stalk color by } \\
\text { a device, lux }\end{array}$ & $\begin{array}{c}\text { Experiment 10 } \\
\text { a device, lux }\end{array}$ \\
\hline 1 & 54.0 & 54.0 & 54.0 \\
\hline 8 & 52.0 & 53.0 & 53.0 \\
\hline 15 & 52.0 & 53.0 & 52.0 \\
\hline 22 & 51.0 & 52.0 & 51.0 \\
\hline 29 & 44.0 & 42.0 & 44.0 \\
\hline 36 & 34.0 & 33.5 & 35.0 \\
\hline 43 & 20.5 & 20.5 & 21.5 \\
\hline 50 & 18.0 & 18.0 & 18.5 \\
\hline
\end{tabular}

Note that the state of the color of the stem «light brown» was reached by the stalks on day 43 of aging.
Under such conditions, the value of the indicator of the color of the stalks by a device in the third and ninth experiments was 20.5 lux, in the tenth experiment -21.5 lux. The state of «dark brown (gray)» was reached by stalks on day 50 of aging. The color of the stalks by a device in experiments 3 and 9 was 18.0 lux, in experiment $10-$ 18.5 lux (Table 3 ).

The quality indicators of the fiber from the shale retted stalks of different types of preparation are given in Table 4.

Analyzing the results given in Table 4, we note that according to the length of a handful, experiment 3 (1 kilogram per meter) showed a value of $119 \mathrm{~cm}$, experiment 9 (2 kilograms per meter) $-177 \mathrm{~cm}$; experiment 10 (3 kilograms per meter) $-179 \mathrm{~cm}$.

The breaking load of the long fiber of the hemp from experiment 3 was $25.3 \mathrm{daN}$, which corresponds to the third grade. The breaking load in experiments 9 and 10 corresponded to the second grade and amounted, respectively, to 27.3 daN and 29.5 daN

In terms of the first grade $(30 \mathrm{daN})$, the closest are the indicators of the breaking load from experiment 3, which is due to the greater hygroscopicity of the thicker layer, capable of retaining the moisture, necessary for the progress of microbiological processes of transformation of stalks into retted stalks.

In terms of linear density, the results from all experiments exceed the permissible level (no more than 50 tex), which rendered the fibers non-standard according to the specified indicator.

In terms of the shives content, the greatest value was demonstrated by the fiber from experiment $10(0.8 \%)$, the content of paw and the content of bast strands - from experiments 9 and $10-1.8 \%$ and $4.1 \%$, respectively (Table 4 ).

While aging hemp stalks on a white film without holes, an increase in the thickness of a layer of combed hemp stalks from 1 to 3 kilograms per meter led to a corresponding increase in indicators. Thus, the breaking load increased by $16.6 \%$, linear density - by $20 \%$, the content of shives by $60 \%$, the paw content - by $12.5 \%$, the content of bast strands - by $10.8 \%$. The increase in the thickness of the stalk layer led to a corresponding increase in the hygroscopicity of the belt, which positively affected the microbiological processes in the preparation of retted stalks.

In terms of breaking load, the fiber corresponds to the third grade; linear density - non-standard, by the content of bast strands - to the second grade, by the content of shives and paw - to the first grade. Therefore, the grade of the fiber is non-standard.

Table 4

Quality indicators of hemp long fiber from the shale retted stalks of various preparation options

\begin{tabular}{|c|c|c|c|c|c|c|c|}
\hline $\begin{array}{c}\text { Experi- } \\
\text { ment No. }\end{array}$ & $\begin{array}{c}\text { L handful, } \\
\mathrm{cm}\end{array}$ & $\begin{array}{c}\text { Breaking load, } \\
\text { daN }\end{array}$ & $\begin{array}{c}\text { Linear den- } \\
\text { sity, tex }\end{array}$ & $\begin{array}{c}\text { The content of } \\
\text { shives, } \%\end{array}$ & $\begin{array}{c}\text { The content of } \\
\text { paw, } \%\end{array}$ & $\begin{array}{c}\text { The content of } \\
\text { bast strands, } \%\end{array}$ & Grade \\
\hline 3 & 119 & 25.3 & 110.0 & 0.5 & 1.6 & 3.7 & non-standard \\
\hline 9 & 177 & 27.3 & 88.0 & 0.7 & 1.8 & 4.1 & non-standard \\
\hline 10 & 179 & 29.5 & 132.0 & 0.8 & 1.8 & 4.1 & non-standard \\
\hline 14 & - & 25.6 & 110 & 1.5 & 0.7 & 3.6 & non-standard \\
\hline
\end{tabular}




\section{Discussion of research results on the development of hemp harvesting technologies involving belt hemp threshers}

Industrial hemp has two phases of ripeness - technical and biological. The period of the technical ripeness of hemp is characterized by the completion of plant growth in height, the accumulation of straw and fiber harvest, the formation of high-quality properties of the fiber part of the crop. This period coincides with the maturation of single seeds in the lower part of the inflorescences of single-species plants. The biological ripeness of hemp is characterized by full ripening of seeds. The duration between the technical and biological ripeness of hemp varieties is, on average, 25-35 days, and depends on weather conditions during the ripening of seeds and biological properties of the population.

Analyzing the results of experimental studies, we note the defining effect of humidity on the duration of retted stalks preparation. With enough moisture, microbiological processes are more intense. Wet surfaces contribute to the vital activity and spread of bacteria. It is worth noting the possible main sources of moisture under the field conditions:

- liquid moisture (precipitation);

- water and water vapor from the soil, including moisture entering the capillary of the soil and moisture emitting plants;

- water vapor from the air.

A significant source of moisture (main) is air. Under conditions of its high humidity, steam condensation occurs on the soil surface, plant environment.

Condensate precipitation is due to daily changes in atmospheric air temperatures, which are most pronounced under the conditions of the continental climate. At night, the surface of the soil, asphalt, concrete, film, and everything that is placed on them, is cooled and, due to significant thermal conductivity, remain overcooled in the early and, partially, daytime hours. Atmospheric air, appearing to be much more stable in the early hours, relatively quickly enhances heat and moisture content. Due to this, its dew point under certain conditions exceeds the temperature of asphalt, concrete, film, etc., as a result of which the process of condensation of excess moisture occurs.

Moisture condensed on the outer surfaces, due to the action of movable atmospheric air (assimilation), evaporates faster. However, in the dead-type internal openings that characterize tarpaulin, the condensing moisture evaporates slowly and gradually only accumulates.

A film of condensate forms on the surface of the stalks. It flows downwards, increasing the thickness of the water layer. Due to the thermal resistance of the film, the wall temperature is significantly lower than the temperature of the film surface. Under such conditions, on this surface there is a small jump in condensate and steam temperatures. The steam temperature in volume is slightly above the saturation temperature. On horizontal surfaces, the heat transfer of condensation is higher than in vertical surfaces.

Increasing the thickness of the film reduces heat transfer. On a polyethylene film (to a lesser extent, concrete, asphalt), condensate quickly flows down, accumulating in some places.

Tarpaulin contains structural formations that make it possible to retain the droplets of condensed moisture and more evenly distribute it on the surface under study. This can explain better quality indicators of fiber obtained from the retted stalks on tarpaulin compared to other materials.

Increasing the hygroscopic humidity of tarpaulin leads to weight gain (and, or volume), changes in density, electrical conductivity, heat transfer, conditions for the growth of bacteria and microorganisms.

Tarpaulin is characterized by the existence of dependence between high hygroscopicity and its quality indicators. High hygroscopicity leads to a deterioration in the consumer properties of the material. This is a consequence of bacteriological growth, changes in chemical composition, chemical reactions with water vapor, etc.

Materials with very little hygroscopicity (these include films, and, to a certain extent, asphalt and concrete) are also exposed to water vapor of moist air, which manifests itself in surface layers.

Our research proposes ways to solve the problem of increasing the efficiency of further mechanization of the production of hemp seeds, long fiber, and other biological parts of the plant.

Based on the systemic analysis of potential variants of technologies for harvesting, transportation, and primary processing of the entire volume of the biological harvest of industrial hemp, the most rational ways to solve the above problem have been proposed.

The main results of this research include the development of technologies for harvesting hemp with belt hemp threshers. The formation of rolls of mowed hemp stalks, according to the proposed method, is carried out on a belt, which is then transported to the edge of the field for further processing of stalks. Owing to the proposed technical and technological solutions, it is possible to increase, by 1.3-1.7 times, the quality of hemp production, reliability, and stability of technological processes, conditions for processing the entire biological crop with the lowest cost of production, expansion of the range and types of finished products. Real signs are shown by the prospects of mechanization of technological techniques for harvesting part of the crop for the preparation of medicinal products.

The possibility of preparing the retted stalks from combed hemp stalks by spreading out them on materials of various types has been systematically substantiated.

Management of the harvesting process (including the formation of the belt - roll formation), planned (systemic), deep, comprehensive processing of all components of the crop on the edge of the field by semi-stationary machines and equipment is attributed to the main advantages of the proposed technique.

The developed technologies and technical means ensure the processing of the entire volume of the biological hemp crop. Under the conditions of their implementation, the number of runs by harvesting machines is reduced, it is possible to free fields per year of seed harvesting, as well as to manage the processes of roll formation and aging of stalks without losing the quality of the resulting retted stalks.

The scientific and practical interest of further research is in the plane of determining the rheological properties of the material of the belt for the transportation of rolls, the study of the influence of structural parameters, the modes of operation of the harvesting machine, as well as other factors, on the power of the roll, which is formed when the unit enters and exits the field line.

\section{Conclusions}

1. Technological schemes of hemp harvesting with belt hemp threshers have been developed. It is proposed to form a roll of mowed hemp stalks on the belt and tramp it to the 
edge of the field for further processing. This makes it possible to significantly improve the efficiency of mechanized processes of harvesting and processing the entire biological harvest of hemp and other crops.

The technological scheme of hemp harvesting with the possibility of obtaining raw materials for long fiber and therapeutic preparations has been devised. Two-phase harvesting (for seeds and fiber) is proposed to be implemented using belt hemp threshers by stationary (semi-stationary) complexes. The specified technologies create favorable conditions for managing the process of roll formation of hemp stalks, increase the level of controllability of production systems. Due to the compact placement of crops in specially prepared areas of the field, there are prospects for gradual processing of all parts of the crop.

2 . The possibility of preparing combed hemp retted stalks by spreading out them on materials of various kinds (a white film without holes, concrete, asphalt, tarpaulin fabric) has been systematically substantiated. This makes it possible to devise new, manageable technological techniques and methods for harvesting and initial processing of the entire biological crop.

It was established that according to the quality indicators of the produced fiber, the retted stalks in all experiments were properly aged, the efficiency of its processing for medium and large-stem fractions is high.

The fiber produced in all experiments was characterized by purity, the high indicators of breaking load and handful length. However, the value of linear density in all variants of research exceeded the normative value by $1.65-2.64$ times, which led to attributing the fiber to non-standard according to this indicator. Exceeding the value of the linear density indicator is due to the raw materials used in experiments (large stalks and seeds taken after harvesting), in which the fiber has already become coarser.

3 . The increase in the values of indicators with a corresponding change, from 1 to 3 kilograms per meter, in the thickness of the layer of combed hemp stalks on a white film without holes has been established. The breaking load, under such conditions, increased by $16.6 \%$; the linear density - by $20 \%$; the content of shives - by $60 \%$; the paw content - by $12.5 \%$; the content of bast strands - by $10.8 \%$. The increase in the thickness of the layer of stems led to a corresponding increase in the hygroscopicity of the belt, which had a positive effect on the microbiological processes of retted stalks preparation and the quality indicators of the fiber obtained from them.

1. Tkachenko, S. M., Mokher, Yu. V., Laiko, I. M., Zhuplatova, L. M., Vyrovets, V. H., Mishchenko, S. V. et. al. (2021). Dovidnyk konopliara. Sumy: Ellada, 27.

2. Sheichenko, V., Marynchenko, I., Shevchuk, V., Zadosnaia, N. (2019). Development of Technology for the Hemp Stalks Preparation. Modern Development Paths of Agricultural Production, 223-232. doi: https://doi.org/10.1007/978-3-030-14918-5_24

3. Wasko, J., Kozlovwski, R., Markovski, J. (2004). The state and the perspective of flax and hemp utilization it Poland and in the World. Euroflax, 1, 6-10.

4. Small, E., Marcus, D. (2002). Hemp: A new crop with new uses for North America. Trends in new crops and new uses. ASHS Press, 284-326. Available at: https://www.hort.purdue.edu/newcrop/ncnu02/v5-284.html

5. Réquilé, S., Mazian, B., Grégoire, M., Musio, S., Gautreau, M., Nuez, L. et. al. (2021). Exploring the dew retting feasibility of hemp in very contrasting European environments: Influence on the tensile mechanical properties of fibres and composites. Industrial Crops and Products, 164, 113337. doi: https://doi.org/10.1016/j.indcrop.2021.113337

6. Kolodinsky, J. (1997). Natural fibers. Special Edition, 58-63.

7. Lyalina, N., Yudicheva, O., Votchenikova, O., Berezovskiy, Y. (2020). Prognosis applications nonnarcotic hemp based on the criterial characteristics. Fibres and Textiles, 1, 35-41. Available at: http://vat.ft.tul.cz/2020/1/VaT_2020_1_6.pdf

8. Virovetc, V. G., Laiko, I. M., Kirichenko, G. I. (2007). Modern Hemp Collection As Not Primary Source of Selection Material. Selection, Production Technology and Primary Processing of Flax and Hemp, 4, 35-42.

9. Duque Schumacher, A. G., Pequito, S., Pazour, J. (2020). Industrial hemp fiber: A sustainable and economical alternative to cotton. Journal of Cleaner Production, 268, 122180. doi: https://doi.org/10.1016/j.jclepro.2020.122180

10. Venturi, P., Amaducci, S., Amaducci, M. T., Venturi, G. (2007). Interaction Between Agronomic and Mechanical Factors for Fiber Crops Harvesting: Italian Results-Note II. Hemp. Journal of Natural Fibers, 4 (3), 83-97. doi: https://doi.org/10.1300/j395v04n03_06

11. Carus, M. (2017). The European hemp industry: Cultivation, processing and applications for fibres, shivs, seeds and flowers. European Industrial Hemp Association. Available at: http://eiha.org/media/2017/12/17-03_European_Hemp_Industry.pdf

12. Koropchenko, S. P., Mokher, Yu. V. (2018). Pidsumky naukovo-doslidnykh robit z mekhanichnoi pererobky konopel na pidpryiemstvakh maloho ta serednoho biznesu. Engineering sciences: development prospects in countries of Europe at the beginning of the third millennium. Vol. 2. Riga: Izdevnieciba «Baltija Publishing», 112-137. Available at: https://www.researchgate.net/profile/GrigoriyKovalenko/publication/344882569_ENGINEERINGSCIENCES_DEVELOPMENTPROSPECTSINCOUNTRIESOFEUROPEATTHEBEGINNINGOFTHETHIRDMILLENNIUM/links/5f968fe7299bf1b53e45ea52/ENGINEERINGSCIENCESDEVELOPMENTPROSPECTSINCOUNTRIESOFEUROPEATTHEBEGINNINGOFTHETHIRDMILLENNIUM.pdf

13. GOST 9993-2014. Hemp fiber tow. Specifications. Available at: https://docs.cntd.ru/document/1200119074

14. GOST 10379-76. Scutched hemp. Technical specification. Available at: https://docs.cntd.ru/document/1200020250

15. GOST 6729-60. Tresta konoplyanaya. Tekhnicheskie usloviya. Available at: https://allgosts.ru/65/020/gost_6729-60 